\title{
COVID-19 e a visão
}

https://doi.org/10.21814/uminho.ed.24.17

\section{José M. González-Méijome}

José M. González Méijome (ORCID: 0000-0001-9050-4170) é Professor Catedrático na área disciplinar de Optometria e Ciências da Visão (OCV) do Departamento de Física da Escola de Ciências da Universidade do Minho. É presentemente o responsável pelo Programa Doutoral de OCV. Em 2016 recebeu o prémio de Optometrista Internacional do Ano pela Universidad Politécnica da Catalunha e em 2018 foi agraciado com o prémio de Mérito Científico da UMinho.

\section{Rute J. Macedo de Araújo}

Rute Juliana Macedo de Araújo (ORCID: 0000-0003-3664-4273) leciona como docente na área disciplinar de Optometria da Universidade do Minho e trabalha como optometrista, sendo assistente de investigação no Clinical and Experimental Optometry Reasearch lab (CEORLab) desde 2013. Tem desenvolvido investigação em lentes de contacto, nomeadamente lentes de contacto especiais, irregularidades corneais, qualidade ótica do olho humano, resposta eletrofisiológica da retina e distorção luminosa.

\section{David P. Piñero}

David Pablo Piñero Llorens (ORCID:0000-0002-1546-4807) é investigador Ramón y Cajal e professor do Departamento de Óptica, Farmacologia e Anatomia da Universidade de Alicante. Desenvolve a sua atividade clínica no Departamento de Oftalmologia do Hospital Internacional Vithas Medimar de Alicante. Foi considerado em 2014, pelo The Ophthalmologist, como o 12 o autor científico a nível mundial em publicações sobre visão e o 5o no mundo na área específica da ceratocone. O portal Expertscape considerou-o o segundo maior especialista mundial em topografia da córnea, aberrometria, astigmatismo e paquimetria e o terceiro em refração ocular. 


\section{Gonzalo Carracedo}

Juan Gonzalo Carracedo Rodríguez (ORCID: 0000-0003-0054-1731) é Professor Titular da Faculdade de Óptica e Optometria da Universidade Complutense de Madrid, sendo Vice-Reitor de assuntos clínicos da mesma Universidade, desde 2018. Graduado em Óptica e Optometria, mestre e doutorado em Optometria e Visão é ainda Diretor do UCM Group Research 920777 “Bioquímica Farmacológica do olho” desde 2019.

\section{Maria J. González-García}

Maria J. González-García (ORCID: 0000-0003-3673-0585) é Professora Senior de Optometria na Universidade de Valladolid e membro do Instituto Universitário de Oftalmobiología Aplicada (IOBA) da Universidade de Valladolid, desde 1994, onde dirige a unidade de lentes de contato. Leciona na Escola de Optometria na área de lentes de contato há mais de 20 anos e dedica grande parte de seu tempo à investigação no Grupo de Superfície Ocular da IOBA. 


\section{RESUMO}

Durante o recente período pandémico e de confinamento observou-se um aumento do interesse pelos aspetos da saúde ocular. Por um lado, sabe-se que o olho poderá ser uma das vias de acesso do vírus ao organismo, tendo despertado um especial interesse pelos eventuais efeitos que esta via possa causar diretamente. Por outro lado, os putativos riscos que poderia implicar o uso de lentes de contacto, e ainda o possível aumento de sintomas e sinais na superfície ocular e/ou de fadiga ocular advindos do aumento do uso de dispositivos eletrónicos e redução do tempo ao ar livre, foram temas de ampla discussão.

Para analisar alguns destes aspetos foram distribuídos (em formato online) dois inquéritos em Portugal e Espanha para averiguar a frequência, intensidade e possíveis mudanças nos sintomas de superfície ocular e de fadiga ocular associada ao confinamento, teletrabalho e tele-estudo. Apenas se apresentam neste trabalho os resultados dos inquéritos aplicados em língua portuguesa e respondidos a partir do território nacional.

Os inquéritos de superfície ocular e de fadiga ocular foram respondidos por mais de 1800 pessoas no território nacional de Portugal. Perto de 50\% dos inquiridos consideram que os seus sintomas relativos à superfície ocular se mantiveram inalterados, perto de $30 \%$ considera que aumentaram de forma ligeira ou moderada, enquanto que perto de $20 \%$ consideram que os mesmos diminuíram durante o confinamento. $\mathrm{O}$ inquérito de fadiga ocular mostrou que aproximadamente $40 \%$ dos inquiridos mantiveram o mesmo nível de fadiga ocular enquanto que $30 \%$ mostrou um aumento ligeiro ou moderado da fadiga ocular sendo marginal a proporção dos que referiram uma diminuição da sintomatologia.

Concluiu-se que os sintomas e sinais da superfície ocular e de fadiga ocular aumentaram a sua frequência e intensidade durante o curto período de confinamento em Portugal. São ainda dadas recomendações à população e profissionais de saúde ocular para enfrentar eventuais situações similares no futuro. 


\section{INTRODUÇÃO}

A doença do coronavírus (COVID-19) causada pelo novo coronavírus SARS-CoV-2 acede ao corpo humano principalmente por via respiratória, afeta o sistema respiratório causando uma pneumonia de caraterísticas e gravidade particulares e atinge outros órgãos e tecidos em todo o corpo. O modo de entrada requer que os tecidos que contactam com o vírus possuam a enzima conversora da angiotensina 2 (ACE-2) para poder entrar nas células através da interação com a proteína $S$ (do termo spike em inglês, figura 1) presente na superfície do vírus e que lhe dá a aparência caraterística de "coroa de espinhos" por todos conhecida. Aparentemente, só assim o vírus se consegue replicar aumentando a carga viral, predispondo o hospedeiro humano a padecer a doença COVID-19 e transmitindo-a a outros mesmo antes de apresentar qualquer sintoma (Huang et al, 2020). O recetor ACE-2 está presente em células dos epitélios, microglia e tecido neural (Machhi et al, 2020).
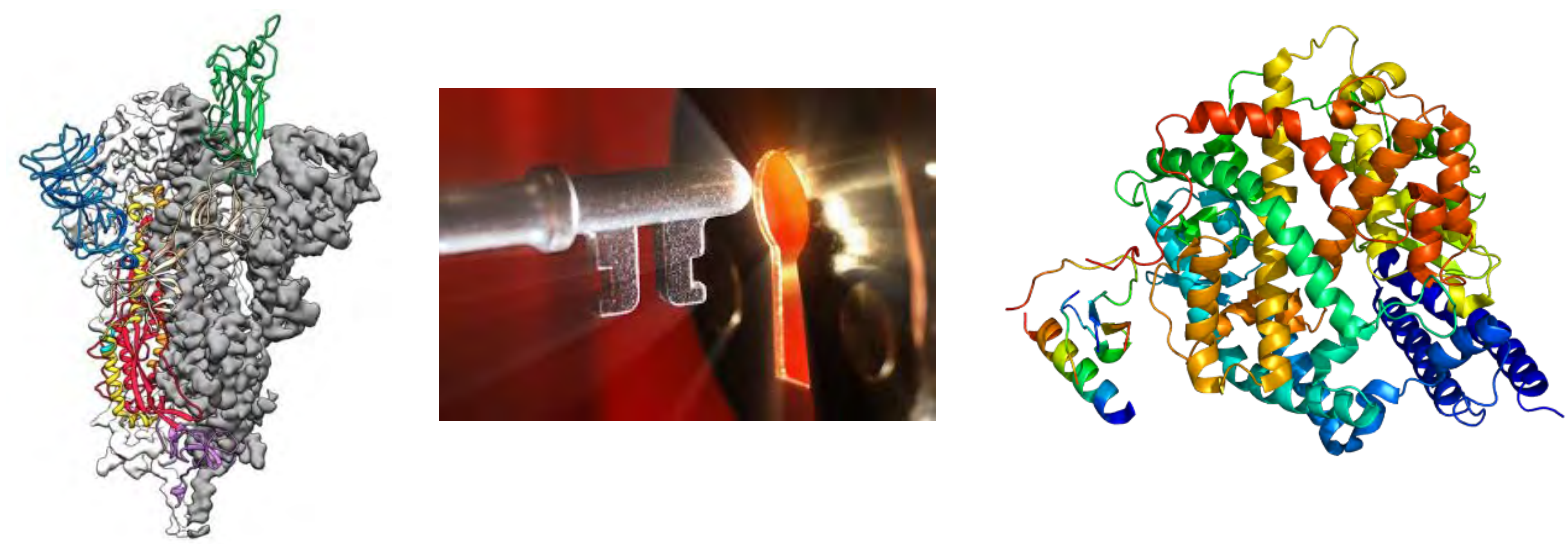

Figura 1. A invasão celular pelo novo coronavírus SARS-CoV-2 requer que as células alvo possuam a enzima conversora da angiotensina 2 (ACE2) para poder invadi-la (estrutura molecular representada à direita da imagem), utilizando para isso a proteína $S$ presente na membrana do vírus (estrutura à esquerda da imagem).

Embora existam no olho tecidos com o ACE-2, tornando assim possível a contaminação por via ocular, as evidências mais recentes mostram que o olho não deverá ser uma via de entrada preferencial para o novo coronavírus (Qing et al, 2020; Liu et al, 2020). Os efeitos diretos da doença no olho têm sido identificados na retina bem como na superfície ocular na forma de inflamaçóes como a conjuntivite. No entanto, os sintomas oculares associados à doença da COVID-19 são relativamente infrequen- 
tes e têm sido observados principalmente em pacientes com a patologia já diagnosticada (Chen et al, 2020). Apesar de alguns estudos de caso terem reportado uma prevalência de sintomas oculares de perto de 30\% em doentes com COVID-19 (Wu et al, 2020), os estudos com maiores amostragens, apontam para uma incidência de menos de 1\% (Guan et al, 2020; Loffredo et al, 2020). À data atual de redação deste escrito, as complicações oculares continuam a não constar dos sintomas e sinais frequentes de COVID-19 (Wang et al, 2020), em nenhum dos modos de apresentação clínica considerados mais recentemente (Machhi et al, 2020).

A figura 2 mostra a anatomia macroscópica do olho humano. A investigação relacionada com o olho e a visão tem identificado alteraçóes ao nível da retina, a camada sensível à luz no nosso olho, bem como a inflamação da conjuntiva da superfície ocular.
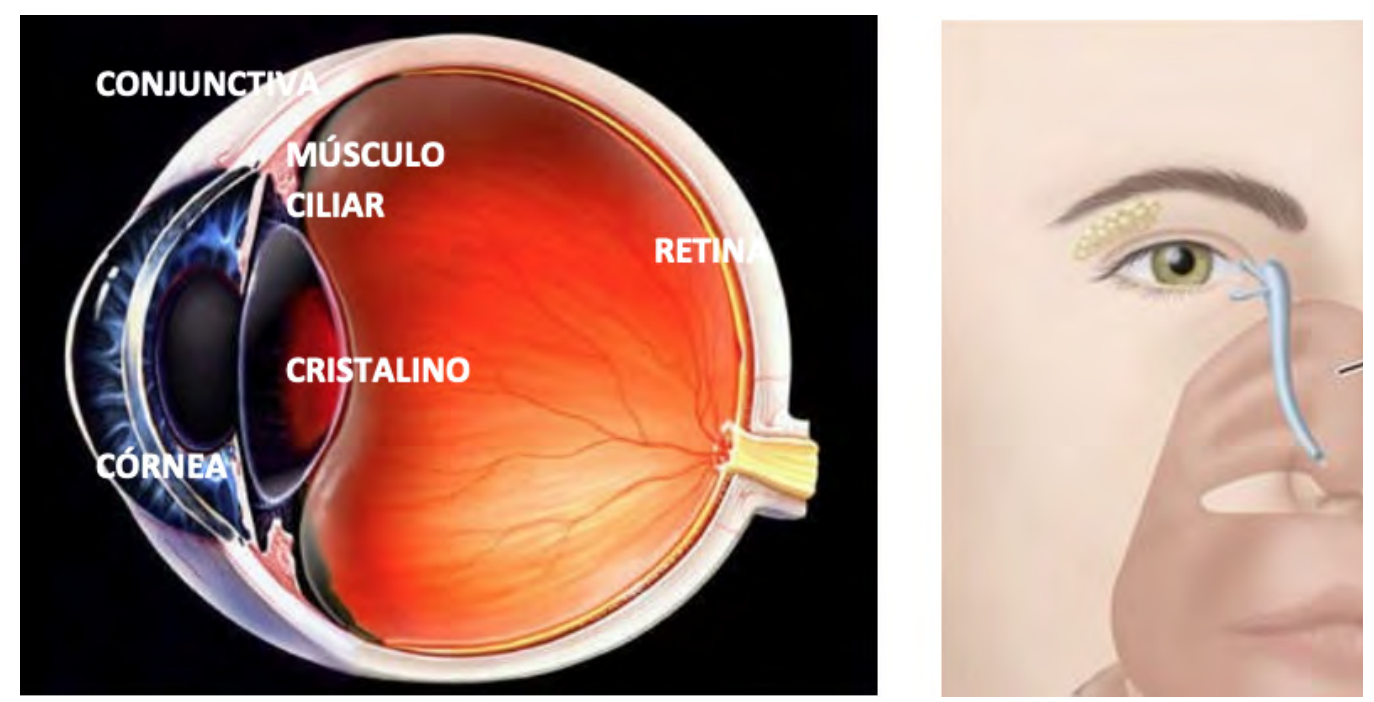

Figura 2. O olho humano e as suas partes relevantes para a interação com o SARS-CoV-2 e a patologia COVID-19. Este pode implicar os epitélios da córnea e conjuntivas bulbar (que cobre a parte branca do olho) e palpebral (que cobre a parte interna das pálpebras em contacto com o olho), assim como das vias que comunicam o olho com a cavidade nasal e nos tecidos da retina, nomeadamente no epitélio pigmentar e eventualmente nos tecidos neurais da retina. O cristalino pode sofrer alterações na sua forma e mudar a potência do olho tornando a visão de longe desfocada depois de períodos prolongados de trabalho em visão próxima devido ao espasmo (atividade excessiva) do músculo ciliar.

Durante os últimos meses a investigação relacionada com este vírus e a patologia a si associada tem aumentado exponencialmente, acumulando à data da escrita deste texto mais de 56.000 artigos indexados na base dados de investigação biomédica do 
Congresso dos Estados Unidos (Pubmed), aumentado ao ritmo de mais 1500 artigos por semana (https://pubmed.ncbi.nlm.nih.gov/).

O olho tem estado na mira dos clínicos e investigadores desde o primeiro momento. Por um lado, o olho tem sido apontado simultaneamente como uma possível porta de entrada do vírus no organismo através das suas mucosas, mas também como um alvo de afetação do novo coronavírus. Por outro lado, as próprias atividades visuais sofreram alteraçôes significativas durante o confinamento. Ao período de confinamento ficou associado o fenómeno do teletrabalho e/ou tele-estudo, o que implica um esforço visual prolongado, quer seja pela utilização de computadores e outros dispositivos de visualização de dados durante longas horas por dia, quer seja por uma redução drástica de atividades ao ar livre. Deste modo, é possível que a visão seja afetada de diversos modos. A utilização intensiva destes dispositivos pode agravar os sintomas de secura ocular, a aparição de sinais como vermelhidão ou intolerância ao uso de lentes de contacto. A própria doença pode estar associada a uma afetação ocular direta, nomeadamente das mucosas, com desenvolvimento de quadros clínicos de irritação ocular e conjuntivite. Por outra parte, a privação de exposição a atividades ao ar livre e o consequente aumento de atividades em visão de perto pode estimular o aumento ou aparecimento da miopia nos indivíduos mais jovens. (Wolffsohn et al, 2019).

Este texto contém as principais informaçóes veiculadas pelos autores durante a pandemia em diversos fóruns para especialistas e não especialistas, incluindo uma palestra no âmbito da iniciativa das Casas do Conhecimento da UMinho "Combater a pandemia com UM conhecimento", Saúde Visual em Tempo de COVID-19. Relata ainda algumas conclusóes preliminares da aplicação de dois inquéritos relativos aos sintomas de desconforto e fadiga visual sentidos pela população durante o confinamento. Este estudo foi desenvolvido para avaliar o impacto do confinamento decorrente da pandemia causada pela doença COVID-19, na superfície ocular, no uso de lentes de contacto e nos sintomas de fadiga ocular e degradação da visão. 


\section{MÉTODO}

Entre os meses de abril e junho aplicaram-se dois inquéritos na plataforma Google Forms para tentar identificar os sintomas e sinais observados pela população durante $\mathrm{o}$ período de confinamento que ocorreu na sequência da declaração do estado de emergência e "estado de alarme" em Portugal e Espanha, respetivamente. Um dos inquéritos focou-se nos sintomas e sinais da superfície ocular enquanto que o segundo se focou nos sintomas e sinais de fadiga visual. Ambos os inquéritos foram aplicados em Português e Castelhano e podiam ser respondidos por qualquer pessoa de forma anónima. Não foi recolhida qualquer informação que pudesse identificar o participante.

O inquérito de superfície ocular era integrado por 32 questóes das quais 7 questôes eram relativas à caraterização demográfica e geográfica dos inquiridos, 8 relativas aos hábitos de uso de lentes de contacto, e 4 relativas à frequência e intensidade dos sintomas oculares durante o período de confinamento, entre outras.

$\mathrm{O}$ inquérito de fadiga ocular incluiu ao todo 44 questôes das quais 22 pretendem avaliar sintomas de má coordenação ocular ou problemas do sistema acomodativo (sistema que utilizamos em atividades em visão de perto). Outras questões visaram caraterizar o posto de teletrabalho dos inquiridos bem como os seus sintomas de fadiga ocular e irritação ocular. Em ambos os inquéritos se questionou aos inquiridos acerca da possibilidade de esses sintomas piorarem no final do dia ou terem piorado durante o confinamento.

Os inquéritos foram distribuídos pelos investigadores através das plataformas de e-mail institucionais das academias envolvidas bem como através das redes sociais e contactos profissionais.

$\mathrm{Na}$ análise dos resultados a apresentar neste texto apenas são mostrados dados relativos aos inquéritos aplicados em língua portuguesa e apenas das respostas recebidas em território nacional. 


\section{RESULTADOS}

Foram obtidas perto de 10.000 respostas. A tabela 1 apresenta o número de respostas para cada uma das versões dos inquéritos. Em Portugal observou-se uma distribuição de género próxima dos 50:50 para o sexo masculino e feminino, o que se aproxima da distribuição presente na população em geral. Conseguiu-se obter uma grande representatividade de idades nos dois inquéritos administrados, sendo a idade média de $39 \pm 12$ anos (de 8 a 88 anos) no inquérito de sinais de sintomas relacionados com a superfície ocular e de $42 \pm 12$ anos (de 17 a 66 anos) no inquérito relativo a sinais e sintomas de fadiga ocular durante o confinamento.

Tabela 1. Número de respostas a ambas as versões dos inquéritos.

$\begin{array}{lccc}\text { Inquérito } & \text { Versão Portuguesa } & \text { Versão Castelhana* } & \text { Total } \\ \text { Superfície Ocular } & 1785 & 6518 & 8303 \\ \text { Fadiga Visual } & 281 & 1123 & 1404 \\ & & & 9707\end{array}$

${ }^{*}$ não analisado neste documento.

Dos inquéritos analisados para o território português, a situação de teletrabalho foi referida por $41 \%$ dos inquiridos enquanto que $15 \%$ referiu encontrar-se em regime de estudo desde casa. A utilização mais intensiva de dispositivos de visualização (ecrãs) foi indicada por $77 \%$ dos inquiridos que referem ter aumentado o número de horas por dia de uso destes dispositivos durante o confinamento. Em 40\% dos inquiridos esse aumento foi de 3 ou mais horas em relação ao habitual em períodos de não confinamento.

Os inquéritos de superfície ocular e de fadiga ocular foram respondidos por 1600 e 350 pessoas no território nacional de Portugal, respetivamente. O inquérito de superfície ocular mostrou que $64 \%$ dos inquiridos utilizam óculos e/ou lentes de contacto para corrigir a visão. De entre os $14 \%$ que usam lentes de contacto, $50 \%$ usaram as suas lentes durante o confinamento, enquanto que outros $50 \%$ não as usou a maioria dos quais apenas por conveniência, referindo que não usam habitualmente as LC em 
casa. Até 7,5\% referiu que não usou as lentes de contacto por ter receio das possíveis consequências negativas e $5 \%$ por recomendação do seu profissional da visão. Perto de $50 \%$ dos inquiridos consideram que os seus sintomas relativos à superfície ocular se mantiveram inalterados, perto de 30\% considera que aumentaram de forma ligeira ou moderada, enquanto que perto de $20 \%$ consideram que os mesmos diminuíram durante o confinamento.

No inquérito de fadiga ocular relacionado com as tarefas de visão de perto observou-se um aumento de alguns sinais e sintomas durante o confinamento. Aproximadamente $1 / 5$ dos inquiridos sentiram mais dores de cabeça (22\%), custava-lhes mais concentrar-se (18\%), tinham sensação de desconforto e cansaço ocular (26\%), sensação de ardência, comichão e lacrimejo (23\%) e visão desfocada (19\%). Quando questionados especificamente sobre a visão a seguir à utilização de ecrãs de visualização como computadores, tablets ou telemóveis, $34,4 \%$ referiu que notaram que a sua visão ficava mais desfocada ao ver ao longe durante alguns segundos ou alguns minutos.

\section{DISCUSSÃO}

Os resultados dos inquéritos aplicados apontam na direção de uma perceção de alterações visuais por parte dos inquiridos. Estas afetam tanto a superfície ocular como a qualidade de visão, particularmente nas tarefas associadas à visão de perto e após o trabalho prolongado com ecrãs de computador ou outros dispositivos de visualização. Metade dos utilizadores de lentes de contacto referem que utilizaram menos as suas lentes durante o confinamento, sendo apontada como principal motivação o facto de não precisarem delas em casa e uma proporção menor por considerar que poderiam acrescentar um risco para a saúde nestas condiçóes.

A investigação relacionada com a COVID-19 e o olho experimentou uma evolução exponencial durante a pandemia como se observa na figura 3. No entanto tratou-se maioritariamente de investigações exploratórias ou de revisão, aportando muito pouca informação que pudesse estabelecer uma ligação direta entre a doença a as suas consequências oculares. Em alguns casos, a urgência por estabelecer ligações entre a COVID-19 e a visão levou a alguns profissionais e mesmo alguns investigadores a dar 
recomendações infundadas e mesmo à divulgação de notícias falsas (Carracedo e Villa, 2020). Foi o caso dos supostos riscos de usar lentes de contacto durante a pandemia. Para isso foram consideradas informaçóes relativamente inconexas e que em muitos casos não obedeciam à realidade nem eram suportadas por qualquer evidência (Jones $e t$ al, 2020). Um dos casos mais paradigmáticos foi originado nas redes sociais por um especialista que divulgou a mensagem da figura 4. Apenas nesse "post" são referidas pelo menos 5 informaçóes erradas ou inexatas (desinformação). Confunde o nome do vírus com o da doença que aquele provoca, atribui vida ao agente patogénico quando ainda permanece em discussão se o vírus tem ou não "vida própria" no sentido biológico da palavra, aponta um tempo de vida/atividade em superfícies que não corresponde ao verdadeiramente encontrado nas investigações (Kampf et al, 2020), investigações essas realizadas com outras estirpes de coronavírus diferentes da que produz a COVID-19, e ainda atribui ao fabrico de lentes de contacto um material (borracha de silicone) que não é usado para o fabrico de lentes de contacto (Warnes et al, 2015), como a notícia de redes sociais parece sugerir.

Os utilizadores de lentes de contacto devem cumprir com estritos procedimentos de limpeza, desinfeção e substituição das suas lentes em todas as circunstâncias e particularmente em períodos de pandemia. A lavagem cuidada das mãos continua a ser a principal ferramenta para evitar contaminação de lentes de contacto e complicações oculares relacionadas. No entanto até à data de finalização deste texto não existe qualquer evidência de que usar lentes de contacto predisponha para um maior risco de contágio pelo novo coronavírus, ou que usar óculos em vez de lentes de contacto acrescente uma proteção adicional. Mesmo quanto aos óculos especificamente concebidos para a proteção ocular, à data de escrita deste texto, não existe evidência sólida de que acrescentem proteção adicional face à COVID-19 (Maragakis, 2020). Em qualquer caso a proteção ocular não deve substituir as estratégias que verdadeiramente reduzem a probabilidade de contrair a doença como são o distanciamento e o uso de máscara, métodos preventivos que demonstraram a sua eficácia numa meta-análise recente (Chu et al, 2020). 

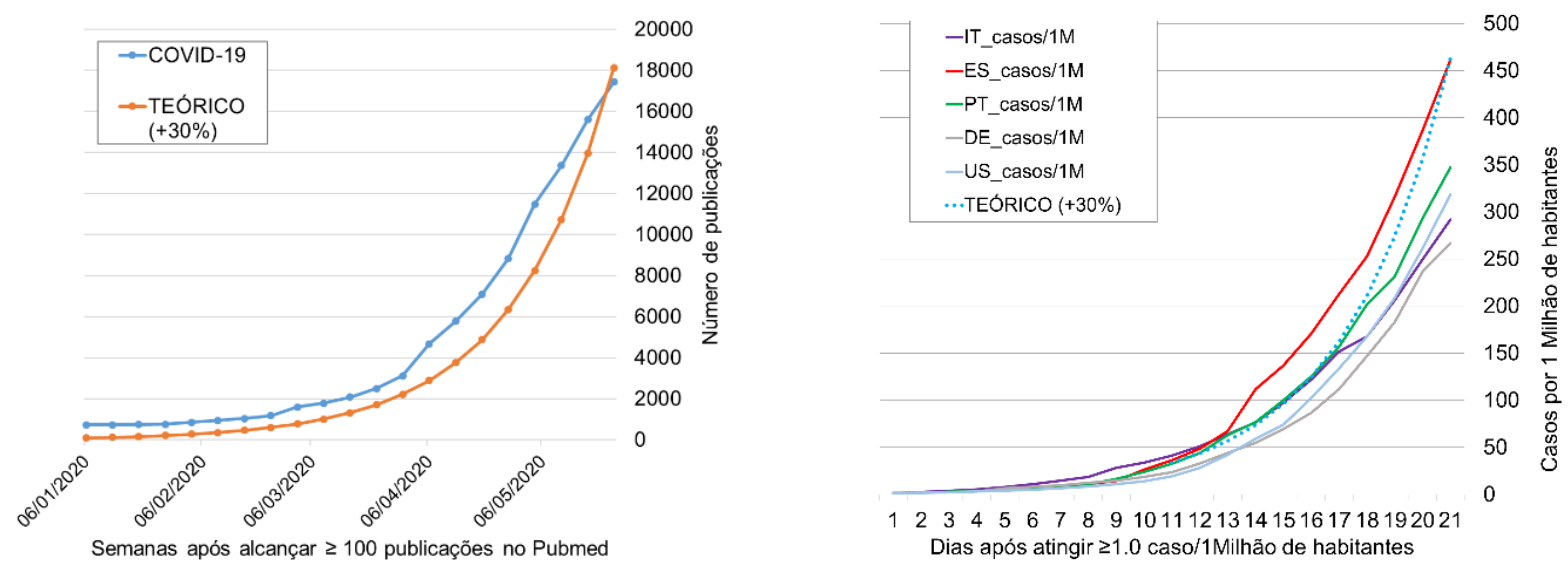

Figura 3. Evolução da investigação relacionada com a COVID-19 publicada na base de dados Pubmed-Medline (https://pubmed.ncbi.nlm.nih.gov). Para referência, apresenta-se a evolução de novos casos reportados em diversos países nos 21 dias a seguir ao momento em que se detetaram 1 caso por milhão (https://www.worldometers.info/coronavirus/). Legenda: IT: Itália; ES: Espanha; PT: Portugal; DE: Alemanha; US: Estados Unidos da América. Modificado de González-Méijiome (2020).

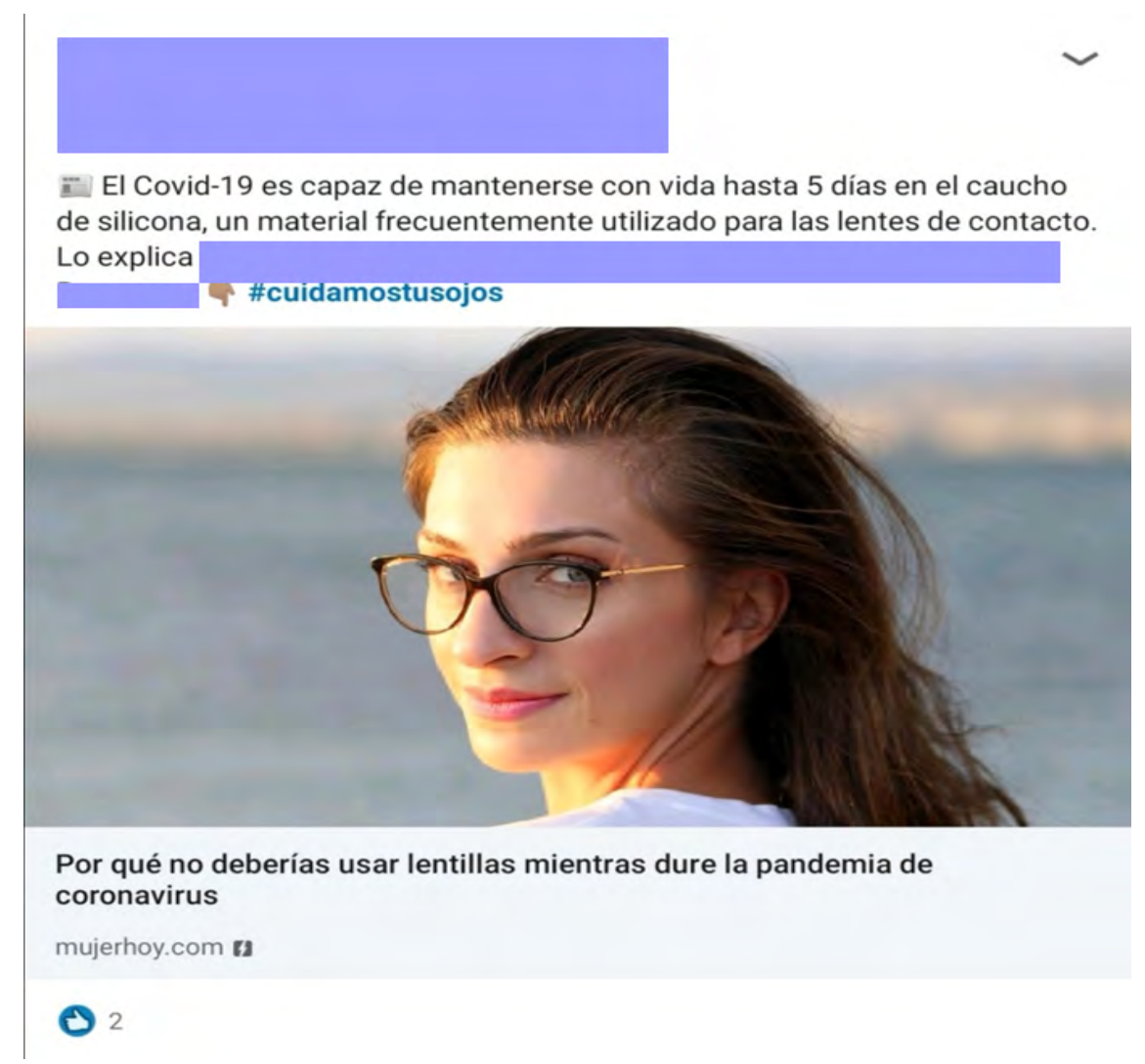

Figura 4. Exemplo de mensagem com informação falsa ou questionável publicada em redes sociais. Tradução para português: "O COVID-19 écapaz de manter-se com vida até 5 dias na borracha de silicone, um material frequentemente utilizado no fabrico de lentes de contacto"; "Por que não deves usar lentes de contacto enquanto durar a pandemia de coronavirus". 
Relativamente ao aumento dos sintomas de superfície ocular reportados pelos inquiridos, estes podem estar relacionados com os períodos de trabalho prolongado com ecrãs de visualização durante o período de confinamento. O teletrabalho e o tele-estudo intensificaram significativamente a utilização de computadores, tablets e telemóveis durante o confinamento. Como mencionado anteriormente, os resultados deste inquérito apontam para um aumento de 3 ou mais horas de uso destes dispositivos durante o confinamento. A relação entre estes dispositivos e o olho seco tem sido observado em diversos estudos (González-Méijome et al, 2007; Portello et al, 2013; Uchino et al, 2013). Segundo alguns autores, até é possível que afete os mais jovens muito antes de estes padecerem de alteraçóes fisiológicas da lágrima tipicamente encontrada em idades mais avançadas (Alves et al, 2008). Um modo de compensar os efeitos adversos do trabalho intenso com computadores em períodos de teletrabalho e tele-estudo passa por incrementar a humidade relativa do ambiente (Wang et al, 2017) entre outras estratégias como o pestanejo frequente (Kim et al, 2020), e os descansos frequentes durante os períodos de trabalho aproveitando esses períodos para descansar das tarefas de visão próxima que criam mais stress visual. As queixas de má visão de longe transitórias depois do trabalho com dispositivos de visualização poderiam eventualmente estar relacionadas com apariçãa ou aumento da miopia. Embora se tenha observado uma possível relação entre a miopia transitória após o trabalho em visão próxima e o aparecimento e progressão da miopia (Lin et al, 2020), os estudos até agora realizados no período de confinamento não permitem confirmar a relação de causa-efeito entre o confinamento e a aparição e/ou progressão da miopia.

Ainda no âmbito da superfície ocular, e como mencionado no início desta discussão, um tema controverso durante os últimos meses tem sido a utilização de lentes de contacto e os eventuais riscos para a saúde ocular e acrescido risco de contágio pelo novo coronavírus. Os resultados deste estudo mostram que cerca de $50 \%$ dos usuários de lentes de contacto usaram menos as suas lentes, mas apenas 7,5\% destes por considerar que poderia envolver algum risco adicional. Numa amostra de dimensão similar no Reino Unido, o professor Philip Morgan da Universidade de Manchester mostrou que $72 \%$ dos que se encontravam em confinamento utilizavam menos as suas lentes, $75 \%$ dos quais o faziam porque consideravam que não as precisavam e $8 \%$ por receio de 
risco de infeção (Morgan et al, 2020). Atualmente não se pode assumir qualquer risco adicional de contaminação por COVID-19 em usuários de lentes de contacto e deve ser realizado o estrito cumprimento das indicações de higiene e manuseamento indicadas pelo profissional de saúde ocular (Willcox et al, 2020), o que é enfatizado também por várias sociedades científicas e profissionais (Gegúndez-Fernández et al, 2020).

As queixas de fadiga ocular em visão de perto observadas neste estudo sugerem que os períodos de confinamento podem induzir um incremento na sintomatologia associada à visão próxima. Para além disso, o potencial impacto do confinamento na progressão da miopia não deve ser ignorado e alguns autores sugerem que se tenha especial atenção a esta possibilidade (Wong et al, 2020).

O estudo realizado apresenta várias limitações. A amostra não é representativa da população portuguesa por estar concentrada principalmente na região norte e centro, com uma baixa representatividade do sul e regiốes autónomas. Os achados documentados não podem ser diretamente atribuídos ao efeito do confinamento pandémico pois não existe uma população controlo que não tenha sido submetida a tal situação que nos permita comparar os resultados. Por último, a informação está baseada na perceção subjetiva dos inquiridos, não tendo sido possível realizar um exame visual que pudesse apontar a presença ou ausência de uma dada alteração visual.

\section{CONCLUSÕES}

Os períodos de confinamento como o experimentado durante a pandemia COVID-19 podem induzir alteraçôes na superfície ocular e provocar fadiga visual. Deste modo a população deve ter acesso facilitado, mesmo que de um modo não presencial, a um profissional da visão (optometrista ou oftalmologista). Só estes profissionais poderão ajudar e aconselhar o melhor modo de atuação sempre que ocorram períodos de sinais e/ou sintomas visuais mais agudos. As novas tecnologias que possibilitam a comunicação via voz e imagem estão ao alcance de uma parte cada vez mais abrangente da população. Mesmo em meios mais desfavorecidos e com dificuldade de acesso aos centros especializados, existem telemóveis e ligações à internet que possibilitam através de diversas aplicações a comunicação. Por sua parte, os profissionais devem promover 
essas vias de comunicação bem como os canais de distribuição de produtos que possam requerer os seus utentes (por exemplo, substituição de óculos ou lentes de contacto, bem como terapêuticas e produtos de alívio de sintomatologia ocular). Em todas estas interaçôes devem sempre ser acautelados os princípios de proteção da privacidade do utente e o profissional deve considerar que, quer seja presencial ou à distância, está sempre obrigado a cumprir com os preceitos éticos e deontológicos que presidem à sua relação com os utentes, nomeadamente o sigilo profissional.

\section{RECOMENDAÇÕES}

Seguem-se algumas recomendações para a população durante períodos de quarentena, confinamento, teletrabalho ou qualquer outra situação que dificulte o acesso a cuidados de saúde visual e tratamentos que deva realizar:

- Sempre que possível, procurar dispor dos produtos que irá precisar durante as seguintes semanas, minimizando desse modo a necessidade de se deslocar a um centro de recolha, ou mesmo vir a precisar de solicitar um envio (como lentes de contacto, líquidos de manutenção das mesmas e lágrimas artificiais, entre outros);

- No caso anterior, considerar a data de validade dos produtos para propósitos de compensação visual e não acumular quantidades excessivas que possam ficar fora de prazo ou obsoletas;

- Assegurar-se que tem um contacto telefónico ou por outro meio de teleconsulta para contatar o profissional da visão que o/a acompanha;

- Questionar o profissional da visão se existe algum teste de rastreio remoto que possa realizar para detetar atempadamente uma evolução da sua situação clínica. Exemplo disso são as tabelas de medida da acuidade visual, testes de rastreio de alterações da visão central e campo visual, testes de rastreio do erro refrativo, etc.;

- Em todos os casos anteriores o utente deve entender que não se trata de testes diagnósticos, apenas de testes de rastreio e deve dar conhecimento do seu resultado 
ao profissional da visão sempre que entender que obteve um valor anómalo. Nunca, em caso algum deve tomar medidas de autotratamento sem antes contatar o seu profissional da visão;

- Durante os períodos de trabalho mais intensivo com computadores ou outros dispositivos de visualização, as pessoas devem realizar descansos visuais regulares. Isto implica que a cada 30, 60 ou 90 minutos, façam um descanso de vários minutos, olhando para longe, pestanejando repetidamente antes de continuar a tarefa;

- Deve garantir uma posição confortável no seu posto de teletrabalho, evitando a incidência de luz direta sobre o ecrã do seu dispositivo de visualização (ecrã), mantendo com aquele uma distância mínima de pelo menos 50 centímetros, e assegurando-se que o ecrã se situa mais baixo que a altura dos seus olhos;

- Evitar trabalhar por períodos prolongados em salas com baixa humidade relativa, particularmente em tarefas que exigem um esforço visual intenso como é o caso do tele-estudo e/ou teletrabalho;

- Se precisar de aplicar gotas oculares ou lágrimas artificiais para tratamento ou alívio de sintomas oculares deve fazê-lo de acordo com as pautas de uso que the foram recomendadas. Se notar que está a precisar de aplicar o tratamento mais frequentemente do que era habitual, deve informar o seu profissional da visão;

- Profissionais, utentes e a população em geral devem informar-se junto de fontes confiáveis, cientes de que em períodos críticos como os que vivemos irão proliferar notícias às quais não devemos dar credibilidade sem antes consultar as indicaçôes das autoridades de saúde e os especialistas ao nosso alcance. 


\section{REFERÊNCIAS}

Alves. M.; Dias A.C.; Rocha E.M. (2008). Dry eye in childhood: epidemiological and clinical aspects. Ocul Surf. 6(1), 44-51.

Carracedo, G.; Villa-Collar, C. (2020). From evidence to fake news.J Optom.S1888-4296(20)30085-6. https:// doi.org/10.1016/j.optom.2020.07.003.

Chen, 1.; Deng, C.; Cheng, X.; Zhang, X.; Chen, B.; Yu, H.; Qin, Y.; Xiao, K.; Zhang, H.; Sun, X. (2020). Ocular manifestations and clinical characteristics of 534 cases of COVID-19 in China: A cross-sectional study. medRxiv. https://doi.org/10.1101/2020.03.12.20034678.

Chu, D.K.; Akl, E.A.; Duda, S.; Solo, K.; Yaacoub, S.; Schünemann, H.J. (2020). COVID-19 Systematic Urgent Review Group Effort (SURGE) study authors. Physical distancing, face masks, and eye protection to prevent person-to-person transmission of SARS-CoV-2 and COVID-19: a systematic review and metaanalysis. Lancet. 395(10242), 1973-1987.

Gegúndez-Fernández J. A.; Zarranz-Ventura, J., Garay-Aramburu, G.; Muñoz-Negrete, F.J.; Mendicute Del Barrio, J.; Pablo-Júlvez, L.; García-Delpech, S.; López-Alemany, A.; Arnalich-Montiel, F.; Cordero-Coma, M.; Cárceles, J.A. (2020). Sociedades oftalmológicas españolas. Recommendations for eye care during the alarm state by the coronavirus disease pandemic COVID-19. Arch Soc Esp Oftalmol. 95(6), 300-310.

González-Méijome, J.M.; Parafita, M.A.; Yebra-Pimentel, E.; Almeida, J.B. (2007). Symptoms in a population of contact lens and noncontact lens wearers under different environmental conditions. Optom Vis Sci. $84(4)$, 296-302.

González-Méijome, J.M. (2020). Journal of Optometry in Emerging Sources Citation Index (ESCI) and peerreview process during COVID-19 Pandemic.J Optom. 13, 210-2012.

Huang, Y.; Yang, C.; Xu, X.F.; Xu, W.; Liu, S.W. (2020). Structural and functional properties of SARS-CoV-2 spike protein: potential antivirus drug development for COVID-19. Acta Pharmacol Sin. 41(9), 1141-1149. http://doi.org/10.1038/s41401-020-0485-4.

Jones, L.; Walsh, K.; Willcox, M.; Morgan, P.; Nichols, J. (2020). The COVID-19 pandemic: Important considerations for contact lens practitioners. Cont Lens Anterior Eye. 43(3), 196-203.

Kampf, G.; Todt, D.; Pfaender, S.; Steinmann, E. (2020). Persistence of coronaviruses on inanimate surfaces and their inactivation with biocidal agents.J Hosp Infect. 104(3), 246-251.

Kim, A.D.; Muntz, A.; Lee, J.; Wang, M.T.M.; Craig, J.P. (2020). Therapeutic benefits of blinking exercises in dry eye disease. Cont Lens Anterior Eye. S1367-0484(20)30087-4.

Lin, Z.; Vasudevan, B.; Liang, Y.B.; Zhou, H.J.; Ciuffreda, K.J. (2020). The association between nearworkinduced transient myopia and progression of refractive error: A 3-year cohort report from Beijing Myopia Progression Study.J Optom. S1888-4296(20)30078-9. https://doi.org/10.1016/j.optom.2020.05.004. 
Liu, Z.; Sun, C.B. (2020). Conjunctiva is not a preferred gateway of entry for SARS-CoV-2 to infect respiratory tract. JMed Virol. 10.1002/jmv.25859. https://doi.org/10.1002/jmv.25859.

Machhi, J.; Herskovitz, J.; Senan, A.M.; Dutta, D.; Nath, B.; Oleynikov, M.D.; Blomberg, W.R.; Meigs, D.D.; Hasan, M.; Patel, M.; Kline, P.; Chang, R.C.; Chang, L.; Gendelman, H.E.; Kevadiya, B.D. (2020). The Natural History, Pathobiology, and Clinical Manifestations of SARS-CoV-2 Infections.J Neuroimmune Pharmacol. 15(3), 359-386. https://doi.org/10.1007/s11481-020-09944-5.

Maragakis, L.L. (2020). Eye Protection and the Risk of Coronavirus Disease 2019: Does Wearing Eye Protection MitigateRisk in Public, Non-Health Care Settings? [published online ahead of print, 2020 Sep 16].JAMA Ophthalmol. https://doi.org/10.1001/jamaophthalmol.2020.3909.

Portello,J.K.; Rosenfield, M.; Chu, C.A. (2013). Blink rate, incomplete blinks and computer vision syndrome. Optom Vis Sci. 90(5), $482-7$.

Qing, H.; Li, Z.; Yang, Z.; Shi, M.; Huang, Z.; Song, J.; Song, Z. (2020). The possibility of COVID-19 transmission from eye to nose. Acta Ophthalmol. 98(3), e388. https://doi.org/10.1111/aos.14412.

Uchino, M.; Yokoi, N.; Uchino, Y.; Dogru, M.; Kawashima, M.; Komuro, A.; Sonomura, Y.; Kato, H.; Kinoshita, S.; Schaumberg, D.A.; Tsubota, K. (2013). Prevalence of dry eye disease and its risk factors in visual display terminal users: the Osaka study. Am J Ophthalmol. 156(4), 759-66.

Wang, D.; Hu, B.; Hu, C.; Zhu, F.; Liu, X.; Zhang, J.; Wang, B.; Xiang, H.; Cheng, Z.; Xiong, Y.; Zhao, Y.; Li, Y.; Wang, X.; Peng, Z. (2020). Clinical Characteristics of 138 Hospitalized Patients With 2019 Novel Coronavirus-Infected Pneumonia in Wuhan, China.JAMA. 323(11), 1061-1069.

Wang, M.T.M.; Chan, E.; Ea, L.; Kam, C.; Lu, Y.; Misra, S.L.; Craig, J.P. (2017). Randomized Trial of Desktop Humidifier for Dry Eye Relief in Computer Users. Optom Vis Sci. 94(11), 1052-1057.

Warnes, S.L.; Little, Z.R.; Keevil, C.W. (2015). Human Coronavirus 229E Remains Infectious on Common Touch Surface Materials. mBio. 6(6), e01697-15.

Willcox, M.D.; Walsh, K.; Nichols, J.J.; Morgan, P.B.; Jones, L.W. (2020). The ocular surface, coronaviruses and COVID-19. Clin Exp Optom. 103(4), 418-424.

Wolffsohn, J.S.; Flitcroft, D.I.; Gifford, K.L.; Jong, M.; Jones, L.; Klaver, C.C.W., Logan, N.S.; Naidoo, K.; Resnikoff, S.; Sankaridurg, P.; Smith, E.L.; Troilo, D.; Wildsoet, C.F. (2019). IMI - Myopia Control Reports Overview and Introduction. Invest Ophthalmol Vis Sci. 60(3), M1-M19.

Wong, C.W.; Tsai, A.; Jonas, J.B.; Ohno-Matsui, K.; Chen, J.; Ang, M.; Ting, D.S.W. (2020). Digital Screen Time During COVID-19 Pandemic: Risk for a Further Myopia Boom? Am JOphthalmol. S0002-9394(20)30392-5. https://doi.org/10.1016/j.ajo.2020.07.034.

Wu, P.; Duan, F.; Luo, C.; Liu, Q.; Qu, X.; Liang, L.; Wu, K. (2020). Characteristics of Ocular Findings of Patients With Coronavirus Disease 2019 (COVID-19) in Hubei Province, China.JAMA Ophthalmol. 138(5), 575-578. 